\begin{tabular}{|c|c|c|c|c|c|c|}
\hline \multirow{4}{*}{ Impact Factor: } & ISRA (India) & $=3.117$ & SIS (USA) & $=0.912$ & ICV (Poland) & $=6.630$ \\
\hline & ISI (Dubai, UAE & $=0.829$ & РИНЦ (Russia & $=0.156$ & PIF (India) & $=1.940$ \\
\hline & GIF (Australia) & $=0.564$ & ESJI (KZ) & $=8.716$ & IBI (India) & $=4.260$ \\
\hline & JIF & $=1.500$ & SJIF (Morocco & $=5.667$ & OAJI (USA) & $=0.350$ \\
\hline
\end{tabular}

\section{SOI: $1.1 /$ TAS $\quad$ DOI: $10.15863 /$ TAS \\ International Scientific Journal Theoretical \& Applied Science}

\author{
p-ISSN: 2308-4944 (print) e-ISSN: 2409-0085 (online) \\ Year: 2019 Issue: $08 \quad$ Volume: 76
}

Published: $30.08 .2019 \quad$ http://T-Science.org
QR - Issue

QR - Article

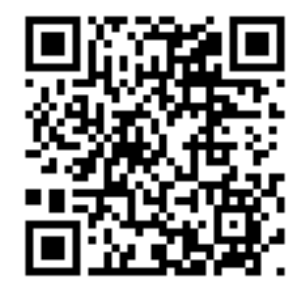

D. K. Omuralieva Naryn State University named after S.Naamatov, Prof. Dr of Economic Science, Kyrgyzstan, Naryn d-omuralieva@yandex.ru

G. A. Kurmanalieva Naryn State University named after S.Naamatov, PhD student on Economic Science, Kyrgyzstan, Naryn, gkurmanalieva@gmail.com

\title{
INSTITUTIONAL GAPS ON PASTURE RESOURCE MANAGEMENT IN THE BORDER TERRITORIES OF THE SOUTH OF KYRGYZSTAN
}

Abstract: Despite the reforms undertaken since the Soviet Union aimed at improving pasture management by creating new formal institutions, institutional gaps are observed that lead to different disagreements among pasture users in the border areas of southern Kyrgyzstan. Despite the availability of the correct requirements and goals in legislative and governing acts to ensure economically viable sustainable use of pastures, some gaps are not consistent with the current practice of pasture farming.

This article discusses possible legislative acts governing pasture resources to identify what institutions exist to manage pasture resources located in the border areas of southern Kyrgyzstan. This article discusses possible regulatory and legislative acts governing pasture resources to identify what institutions exist in pasture management located in the border areas of southern Kyrgyzstan.

Key words: pasture resource management, institutional gap, governing and legislative acts, border areas, south Kyrgyzstan.

Language: Russian

Citation: Omuralieva, D. K., \& Kurmanalieva, G. A. (2019). Institutional gaps on pasture resource management in the border territories of the south of Kyrgyzstan. ISJ Theoretical \& Applied Science, 08 (76), 238-244.

Soi: http://s-o-i.org/1.1/TAS-08-76-33 Doi: crossef https://dx.doi.org/10.15863/TAS.2019.08.76.33

Classifiers: Management.

\section{ИНСТИТУЦИОНАЛЬНЫЕ ПРОБЕЛЫ В УПРАВЛЕНИИ ПАСТБИЩНЫМИ РЕСУРСАМИ НА ПРИГРАНИЧНЫХ ТЕРРИТОРИЯХ ЮГА КЫРГЫЗСТАНА}

Аннотация: Несмотря на проведенные реформы со времен Советского Союза, направленное на улучшение управления пастбищами путем создания новых формальных институтов, наблюдается институциональные пробель, которое приводит к разным разногласиям среди пастбищепользователей на приграничных территориях юга Кыргызстана. Несмотря на наличие правильных предписаний, и поставленных целей в законодательных и нормативных актах для обеспечения экономически жизнеспособное устойчивое использование пастбищ существует ряд недостатков или недоработок, которые не соответствует реальной практике пастбищного хозяйства.

В данной статье рассматриваются возможные нормативно-правовые и законодательные акты, регулирующие пастбищные ресурсы, чтобы выявить, какие институты существует в управлении пастбищами расположенные в приграничных территориях юга Кыргызстана.

Ключевые слова: управление пастбищными ресурсами, институциональный пробел, нормативноправовые и законодательные акты, приграничные территории, юг Кыргызстана. 


\begin{tabular}{llllll} 
& ISRA (India) $=\mathbf{3 . 1 1 7}$ & SIS (USA) $=\mathbf{0 . 9 1 2}$ & ICV (Poland) & $\mathbf{= 6 . 6 3 0}$ \\
Impact Factor: & ISI (Dubai, UAE) $=\mathbf{0 . 8 2 9}$ & PUHL (Russia) $=\mathbf{0 . 1 5 6}$ & PIF (India) & $=\mathbf{1 . 9 4 0}$ \\
& GIF (Australia) $=\mathbf{0 . 5 6 4}$ & ESJI (KZ) $=\mathbf{8 . 7 1 6}$ & IBI (India) & $\mathbf{4 . 2 6 0}$ \\
& JIF & $\mathbf{1 . 5 0 0}$ & SJIF (Morocco) $=\mathbf{5 . 6 6 7}$ & OAJI (USA) & $\mathbf{0 . 3 5 0}$ \\
\hline
\end{tabular}

\section{Введение}

Южные регионы Кыргызстана известны региональной нестабильностью из-за отсутствия демаркации и делимитации границ на некоторых участках приграничных территорий, а так же присутствием частого разногласия за доступ и использование природных ресурсов, как вода и пастбища. Эти разногласия в основном происходят в приграничных территориях юга Кыргызстана, где расположены анклавы соседних стран Таджикистана и Узбекистана.

С распадом Советского Союза произошли большие изменения в аграрном секторе Кыргызстана. Были проведены неоднократные земельные реформы, произошли институциональные изменения на благо рационального использования природных ресурсов как вода и земля. Эти ресурсы были всегда одними из наиболее важных факторов в развитии сельских регионов Кыргызстана и основой экономики страны. В силу природноклиматических условий около $60 \%$ населения традиционно занимается животноводством. Пасторализм остается ключевой сельскохозяйственной деятельностью Кыргызского народа. Естественные пастбищные ресурсы являются национальным богатством Кыргызстана.

Тотальные изменения произошли в управлении пастбищными ресурсами при проведении земельной реформы, где имеет место система общинного управления. В рамках нового законодательства Кыргызской Республики «О пастбищах» (2009) были учреждены новые институциональные структуры - ассоциации пастбищепользователей и пастбищные комитеты в целях обеспечения устойчивого управления пастбищными ресурсами.

Однако, несмотря на то, что в стране принято достаточное количество законодательных актов регулирующее природные ресурсы, в отдельных случаях нормы законодательства, регулирующие пастбищные ресурсы, не позволяют в должной мере оказывать положительное воздействие в управлении пастбищными ресурсами на приграничных территориях в особенности. Таким образом, целью данной статьи является анализ институциональных аспектов, регулирующие пастбищные ресурсы в приграничных территориях на юге Кыргызстана, чтобы понять какие институциональные инструменты существуют для управления пастбищными ресурсами на приграничных территориях юга Кыргызстана.

\section{1. Материалы и методика исследований}

Эмпирическое исследование основывалось на обзоре и анализе документов (например, отчетов, законов и подзаконных актов), связанных c управлением пастбищных ресурсов в Кыргызстане. Анализ документов был использован для обзора и анализа формальных институциональных механизмов в пастбищном секторе Кыргызстана. Национальные законы, официальные указы и правительственные отчеты были пересмотрены, чтобы понять правовые основы реформ. В частности, национальный закон «о пастбищ», принятый в 2009 году после обретения независимости, был тщательно пересмотрен, чтобы улучшить понимание правового положения местных пастбищепользователей и их прав в отношении управления, доступа и использования пастбищных ресурсов. Другие кодексы (например, Земельный кодекс, Налоговый кодекс и Гражданский кодекс), относящиеся к управлению пастбищ, также были тщательно изучены. Наконец, различные указы и правила, которые могут содержать положения, касающиеся пастбищного управления, также рассматривались как часть анализа документов.

\section{2. Институты управления пастбищными} ресурсами (1991-2009)

После распада Советского Союза Кыргызстан претерпел сложное время, но приобрел ценный опыт с точки зрения постсоциалистического перехода, трансформации и институциональных изменений в управлении природными ресурсами, где формальные институты управления природными ресурсами менялись, учитывая проблемы окружающей среды.

1991 год был годом перемен в системе сельского хозяйства Кыргызской Республики. В этом году, после обретения независимости, был подписан Указ Президента о принятии Закона «О крестьянских хозяйствах», которое стало началом земельной реформы. Согласно данному закону все крестьянские хозяйства были наделены правом на получение земли.

Позже, в 1995 году был подписан следующий Указ Президента «О мерах по дальнейшему развитию и государственной поддержке земельной и аграрной реформы в Кыргызской Республике». Данный указ уполномочивает Министерство сельского хозяйства и продовольствия управлять и сдавать в аренду отгонные, интенсивные и присельные пастбища по согласованию с местными государственными администрациями (прототипы Айыльного Аймака) и сельским комитетом по земельной и аграрной реформе. Несмотря на то, что в 1999 году был принят новый Земельный кодекс, который ввел частную собственность на земли сельскохозяйственного назначения, пастбища остались в государственной собственности. 


\begin{tabular}{|c|c|c|c|c|c|c|}
\hline \multirow{4}{*}{ Impact Factor: } & ISRA (India) & $=3.117$ & SIS (USA) & $=0.912$ & ICV (Poland) & $=6.630$ \\
\hline & ISI (Dubai, UAI & $=0.829$ & РИНЦ (Russia & $=0.156$ & PIF (India) & $=1.940$ \\
\hline & GIF (Australia) & $=0.564$ & ESJI (KZ) & $=8.716$ & IBI (India) & $=4.260$ \\
\hline & JIF & $=1.500$ & SJIF (Morocce & $=5.667$ & OAJI (USA) & $=0.350$ \\
\hline
\end{tabular}

Далее, 4 июня 2002 года было утверждено постановлением Правительства Кыргызской Республики (№ 360) «Положение о порядке предоставления пастбищ для аренды и использования». В рамках данного положения пастбища делятся на три категории: отгонные, интенсивные и присельные пастбища, где общие площади и границы определяются в порядке землеустройства, а пастбища находящиеся в составе лесного фонда - в порядке Лесного Хозяйства. Таким образом, данное положение наложило ответственность за отгонные пастбища - областные государственные администрации, пастбищ расположенных в зоне интенсивного пользования - районным государственным администрациям и сельские управы (орган исполнительной власти сельского местного самоуправления) были ответственны за присельные пастбища. То есть, ответственность каждого уполномоченного органа за отдельные пастбища заключалась в основном в разработке комплексных планов по перераспределению, использованию и охране пастбищ и в организации конкурсов для выдачи разрешений на предоставление в аренду пастбищ. В свою очередь, границы пастбищ всей категории устанавливаются органами Государственного агентства по регистрации прав на недвижимость имущество при Правительстве Кыргызской Республики (Госрегистр). Аренда пастбищ предоставляется физическим и юридическим лицам для сельскохозяйственного производства на условиях открытого конкурса сроком от 5 до 10 лет для выпаса скота. Согласно Положению, проведения конкурса является обязательным. Для того, чтобы принять участие в конкурсе, физические или юридические лица должны были обратиться с ходатайством определенному административно-территориальному органу с конкретным запросом какого типа пастбищ (отгонный, интенсивный или присельный) данное лицо желает получить. Только после этих процедур, тот или иной орган начинает рассматривать заявление и готовит документы в Госрегистр, который готовит участок для участия в конкурсе. Это положение было основным законодательным документом регулирующее институциональные рамки и процедуры управления пастбищных ресурсов Кыргызской Республики до принятия нового закона «О пастбищ» который был принят в 2009 году.
- Новый формальный институт управления пастбищныли ресурсами от 2009 года

Новый Закон Кыргызской Республики «О пастбищ» был принят в январе 2009 года. Целью принятия нового закона заключалось в том, чтобы достигнуть более эффективного, равноправного и стабильного управления пастбищными ресурсами наделяя при этом местное сообщество полномочиями в процессе принятия решения. С целью продвижения более устойчивого использования пастбищных ресурсов, новый закон ввел радикальные изменения в системе управления пастбищ. В рамках данного закона, система государственного управления пастбищными ресурсами перешло на общинное управление, где ответственность за управление пастбищными ресурсами были переданы местным общественным организациям пользователей. В соответствии с новым законом все пользователи пастбищ должны объединиться в объединения пастбищепользователей (ОПП), которые в свою очередь формируют собственный исполнительный орган - жайыт комитет (ЖК). С принятием нового закона, система долгосрочного арендного договора на использование пастбищ перешла на систему ежегодной оплаты за каждое поголовье скота - «пастбищный билет». И последнее, новый закон ввел систему планирование и мониторинга по использованию и управлению пастбищными ресурсами.

Согласно закону «О пастбищах» от 2009 года, ново организованные объединения ОПП обладают рядом полномочий и прав в управлении использования пастбищ. Согласно с пунктом 5 статьи 6 данного Закона, жайыт комитеты (ЖК) несут ответственность:

- за разработку и реализацию плана общинного использования пастбищ;

- ежегодного плана использования пастбищ;

- выдачи пастбищных билетов в соответствии с ежегодным планом использования пастбищ;

- установления и сбора платы за использование пастбищ;

- разрешения споров, касающихся использования пастбищ, и

- в осуществление инвестиций в пастбищную инфраструктуру и на содержание пастбищ.

Таблица 1. Формальные институты управления пастбищными ресурсами (1991-2009)

\begin{tabular}{|l|l|l|}
\hline \multicolumn{2}{|c|}{ Правовая норма } & \multicolumn{3}{|c|}{ Децентрализация власти управления } \\
\hline $\begin{array}{l}\text { Земельный кодекс Кыргызской } \\
\text { Республики (1991) }\end{array}$ & $\begin{array}{l}\text { Управление пастбищными ресурсами в зависимости от их } \\
\text { расположения на районном, областном уровнях и Совета }\end{array}$ \\
\hline
\end{tabular}




\begin{tabular}{|c|c|c|c|c|c|c|}
\hline \multirow{4}{*}{ Impact Factor: } & ISRA (India) & $=3.117$ & SIS (USA) & $=0.912$ & ICV (Poland) & $=6.630$ \\
\hline & ISI (Dubai, UAI & $=0.829$ & РИНЦ (Russia & $=0.156$ & PIF (India) & $=1.940$ \\
\hline & GIF (Australia) & $=0.564$ & ESJI (KZ) & $=8.716$ & IBI (India) & $=4.260$ \\
\hline & JIF & $=1.500$ & SJIF (Morocce & $=5.667$ & OAJI (USA) & $=0.350$ \\
\hline
\end{tabular}

\begin{tabular}{|c|c|}
\hline & $\begin{array}{l}\text { министров (постоянный и долгосрочный договор аренды до } 25 \\
\text { лет частным, государственным и коллективным фермерам). }\end{array}$ \\
\hline $\begin{array}{l}\text { Указ Президента Кыргызской } \\
\text { Республики «О земельной и аграрной } \\
\text { реформе» (1993) }\end{array}$ & $\begin{array}{l}\text { Правительственное и Государственное Агентство по Охране } \\
\text { Окружающей Среды и Лесного Хозяйства: пастбища } \\
\text { расположенные на территории Лесного Хозяйства }\end{array}$ \\
\hline $\begin{array}{l}\text { Указ Президента } \text { Кыргызской } \\
\text { Республики «О мерах по дальнейшему } \\
\text { развитию } \text { и государственной } \\
\text { поддержке земельной и аграрной } \\
\text { реформы в Кыргызской Республике» от } \\
3 \text { ноября } 1995 \text { года. }\end{array}$ & $\begin{array}{l}\text { Управление пастбищными ресурсами: } \\
\text { - Сельские комитеты по земельной и аграрной реформе - } \\
\text { присельные пастбища; } \\
\text { Местная Государственная Администрация - } \\
\text { интенсивные пастбища } \\
\text { Местная Государственная Администрация - отгонные } \\
\text { пастбища }\end{array}$ \\
\hline $\begin{array}{l}\text { Земельный } \quad \text { кодекс } \\
\text { Республики, } 2 \text { июня } 1999 \text { года. }\end{array}$ & $\begin{array}{l}\text { Управление пастбищными ресурсами: } \\
\text { • } \\
\quad \text { Местная Государственная } \\
\text { присельные пастбища; } \\
\text { • } \\
\text { Районная администрация - интенсивные пастбища; } \\
\text { Областная администрация - отгонные пастбища }\end{array}$ \\
\hline $\begin{array}{l}\text { Постановление } \\
\text { Кыргызской Республики № } 360 \text { «Об } \\
\text { аренде и использовании пастбищных } \\
\text { угодий» от } 4 \text { июня } 2002 \text { года. }\end{array}$ & $\begin{array}{l}\text { Управление пастбищными ресурсами: } \\
\text { • Местная Государственная Администрация } \\
\text { присельные пастбища; } \\
\text { • Районная администрация - интенсивные пастбища; } \\
\text { - Областная администрация - отгонные пастбища или } \\
\text { Государственное Агентство по Охране Окружающей } \\
\text { Среды и Лесного Хозяйства } \\
\text { (договор аренды на конкурсной основе) }\end{array}$ \\
\hline $\begin{array}{l}\text { Закон Кыргызской Республики от } 26 \\
\text { января } 2009 \text { года № } 30 \text { "О пастбищах" }\end{array}$ & 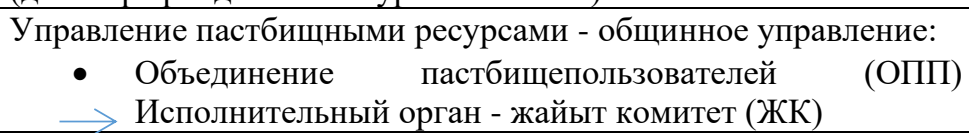 \\
\hline
\end{tabular}

Источник: У.Касымов 2016

Таблица 2. Изменение формальных институтов управления пастбищными ресурсами (2002-2009)

\begin{tabular}{|c|c|c|}
\hline $\begin{array}{c}\text { Внесенные изменения в } \\
\text { пастбищное } \\
\text { законодательство } \\
\end{array}$ & $\begin{array}{c}\text { Ранее действовавшее } \\
\text { пастбищное законодательство } \\
\text { (2002) } \\
\end{array}$ & $\begin{array}{l}\text { Действующее пастбищное } \\
\text { законодательство (2009) }\end{array}$ \\
\hline Ответственность & 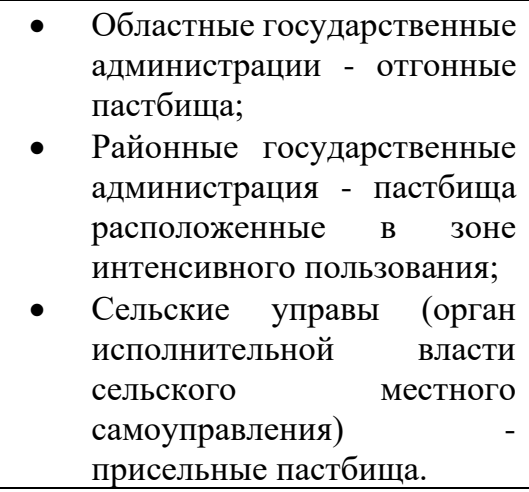 & $\begin{array}{l}\text { Управление всеми типами пастбищ } \\
\text { (интенсивные, отгонные и присельные) } \\
\text { переходит в в объединение } \\
\text { пастбищепользователей (ОПП) и его } \\
\text { исполнительному органу - жайыт } \\
\text { комитет (ЖК); } \\
\text { Лесное Хозяйство - } \\
\text { Пастбища расположенные } \\
\text { территории Государственного лесного } \\
\text { фонда }\end{array}$ \\
\hline $\begin{array}{l}\text { Планирование и мониторинг } \\
\text { использования пастбищ }\end{array}$ & \begin{tabular}{lr}
\multicolumn{2}{l}{ Согласно Постановлению № 360,} \\
общие площади и & границы \\
пастбищ определяются & в ходе \\
землеустроительной & и \\
лесоустроительной деятельности \\
и на основе планов по \\
распределению, использованию и \\
защите пастбищ, которые должны \\
быть подготовлены Гипроземом.
\end{tabular} & 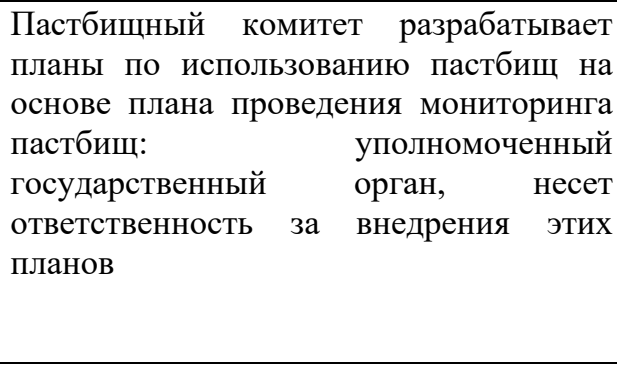 \\
\hline
\end{tabular}




\begin{tabular}{|c|c|c|c|c|c|c|}
\hline \multirow{4}{*}{ Impact Factor: } & ISRA (India) & $=3.117$ & SIS (USA) & $=0.912$ & ICV (Poland) & $=6.630$ \\
\hline & ISI (Dubai, UAE & $=0.829$ & РИНЦ (Russia & $=0.156$ & PIF (India) & $=1.940$ \\
\hline & GIF (Australia) & $=0.564$ & ESJI (KZ) & $=8.716$ & IBI (India) & $=4.260$ \\
\hline & JIF & $=1.500$ & SJIF (Morocco & $=5.667$ & OAJI (USA) & $=0.350$ \\
\hline
\end{tabular}

\begin{tabular}{|c|c|c|}
\hline $\begin{array}{l}\text { Оплата за использование } \\
\text { пастбищ }\end{array}$ & $\begin{array}{l}\text { Арендная плата за пастбищ в } \\
\text { зависимости от арендуемого } \\
\text { пастбищного участка }\end{array}$ & 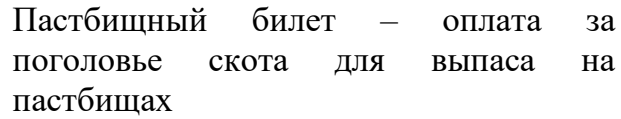 \\
\hline Земельный налог & 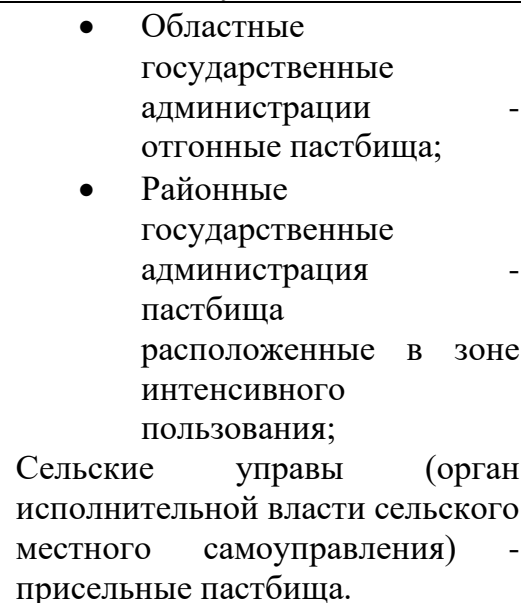 & 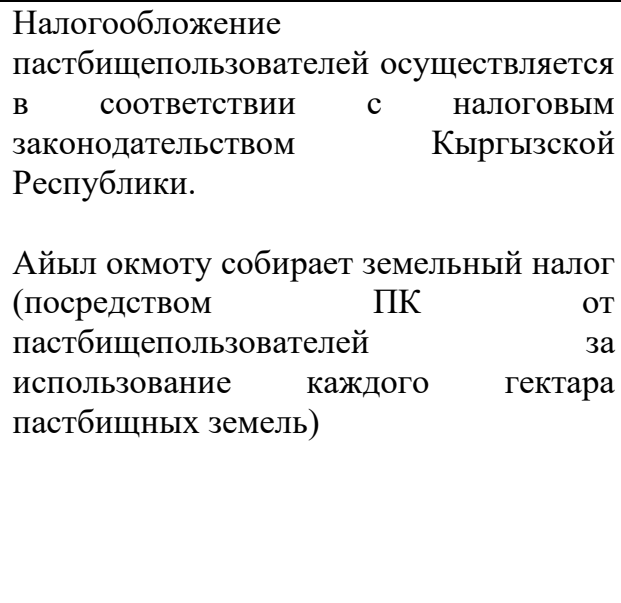 \\
\hline $\begin{array}{l}\text { Распределение пастбищных } \\
\text { угодий }\end{array}$ & $\begin{array}{l}\text { Договор аренды сроком от } 5 \text { до } 10 \\
\text { лет на конкурсной основе }\end{array}$ & $\begin{array}{lcr}\text { Годовое } & \text { соглашение } & \text { между } \\
\text { пастбищным } & \text { комитетом } & \text { и } \\
\text { скотовладельцом } & & \\
\end{array}$ \\
\hline $\begin{array}{lr}\text { Распределение } & \text { Пастбищ } \\
\text { расположенные } & \text { на } \\
\text { территории } & \\
\text { Государственного } & \text { лесного } \\
\text { фонда } & \end{array}$ & Договор аренды & Договор аренды \\
\hline
\end{tabular}

Источник: У.Касымов 2016

\section{3. Результаты исследования и их обсуждение \\ Несмотря на наличие правильных предписаний, и поставленных целей в законодательных и нормативных актах для обеспечения экономически жизнеспособное устойчивое использование пастбищ существует ряд недостатков или недоработок, которые не соответствует реальной практике пастбищного хозяйства.}

Ученые в своих работах отмечали и отмечают ряд критических замечаний в законодательных и правовых актах управления пастбищными ресурсами в Кыргызской республике. Например, Дорре (2012) описывает изменения в пастбищном законодательстве после обретения независимости Кыргызстана бессистемной, так как пастбищепользование в Кыргызстане, в эти годы является классическим примером так называемой «трагедии общин», как описал его Хардин (1968). Первым важным изменением было то, что пастбища могут быть сданы в аренду в краткосрочной, среднесрочной или долгосрочной перспективе частным, государственным и коллективным пользователям. Однако это законодательство не предусмотрела экологические потребности в ротации пастбищ, понимания и предпочтения пастбищепользователей и принятия мер для справедливого и прозрачного доступа к пастбищным угодьям, так как это законодательство было просто скопировано, которое уже использовалось для пахотных земель.

Унделанд (2005) в своей работе отмечает ряд пробелов в изменении в пастбищном законодательстве. Она отмечает, что в Земельном Кодексе от 1999 года, пастбища, расположенные вблизи государственных границ, а также пастбища, которые являются частью пахотных земель и земель для многолетних насаждений могут предоставляться в частную собственность, сильно соответствует политическому восприятию Вашингтонского Консенсуса, призывающего к «приватизации». Политики полагали, что неэффективное управление является результатом слабо определенных прав собственности и что обеспечение индивидуальных прав собственности на землю может улучшить использование ресурсов. Так как управление и использование пастбищ также регулируется другими законодательными актами, такими как Лесной кодекс, Налоговый кодекс; Закон об управлении землями сельскохозяйственного назначения и другие, Унделанд (2005) наблюдает множество противоречий между этими всеми законами, которые способствуют неопределенности, неясности и разночтения различных положений. Далее, она описывает изменения в законодательстве от 2002 года. Унделанд (2005) отмечает, что практика не соответствует правовой 


\begin{tabular}{llllll} 
& ISRA (India) $=3.117$ & SIS (USA) $=\mathbf{0 . 9 1 2}$ & ICV (Poland) & $=\mathbf{6 . 6 3 0}$ \\
Impact Factor: & ISI (Dubai, UAE) $=\mathbf{0 . 8 2 9}$ & PUHЦ (Russia) $=\mathbf{0 . 1 5 6}$ & PIF (India) & $=\mathbf{1 . 9 4 0}$ \\
& GIF (Australia) $=\mathbf{0 . 5 6 4}$ & ESJI (KZ) & $\mathbf{8 . 7 1 6}$ & IBI (India) & $=\mathbf{4 . 2 6 0}$ \\
& JIF & $=\mathbf{1 . 5 0 0}$ & SJIF (Morocco) $=\mathbf{5 . 6 6 7}$ & OAJI (USA) & $\mathbf{0 . 3 5 0}$ \\
\hline
\end{tabular}

базе, в связи с тем, что пастбищепользователи не хотели придерживаться писаному положению и уклонялись от регистрации прав пользования, так как нормы Положения были очень трудновыполнимыми в плане бюрократических процедур, где пастбищепользователи должны были собрать определенные документы для участия в конкурсе. Эта процедура во многих случаях сильно затягивалась, однако согласно Положению, без прохождения заключительного этапа процедуры предоставления аренды регистрации подтверждающего удостоверения использование пастбищного участка является незаконным.

Лим (Lim) 2002, в своей работе подчеркивает, что разделение полномочий между тремя уровнями администрации согласно Земельному Кодексу (1999) Кыргызской Республики привело к разным правилам и процедурам использования различных типов пастбищ. Статическая система арендного договора Положения от 2002 года привело к сложной процедуре, где пасторалисты испытывали сложности в принятии участия в конкурсе, чтобы получить пастбищные участки на законной основе. В свою очередь местные органы власти, тоже испытали недостаток в возможности осуществить и обеспечить соблюдения закона, в результате которого, привело к открытому доступу к пастбищным ресурсам.

\section{4. Выводы и заключение}

В данной статье были рассмотрены все имеющиеся нормативно-правовые, законодательные акты регулирующее пастбищное хозяйство в Кыргызстане. Были рассмотрены формальные институты, принятые со времен Советского Союза и исследование показало, что никаких институциональных аспектов не было принято в управлении пастбищными ресурсами на приграничных территориях.

Таким образом, со своей стороны хотелось бы отметить, что Закон «О пастбищ» от 2009 года, также имеет свои недостатки или недоработки, которое не соответствует реальной практике пастбищного хозяйства, которое было выявлено входе проведения анализа нормативно-правового документа. Высокая текучесть кадров, в результате не приписанных в законе четкого разграничения обязанностей, прав и ответственности между Пастбищным Комитетом и Айыл Окмоту является одной из главной проблемой, которое создает большие препятствие в управлении пастбищными ресурсами. Далее, в законе отсутствует четкие механизмы сбора точных сведений о количестве скота, которое, тоже в свою очередь создает проблемы при сборе оплаты за выпас скота, в результате которого пастбищный комитет не в состоянии увеличить свои доходы и не способствует эффективности их работы. Также, в законе нет формальных механизмов сотрудничества между пастбищным комитетом и администрациями лесных хозяйств, Айыл окмоту соседних Айылных Аймаков и Особо Охраняемых Природных Территорий, которое часто приводит к конфликтам интересов.

И самое главное, несмотря на наличие приграничных территорий, где иностранные скотовладельцы сильно зависят от использования пастбищ на территории Кыргызской Республики, на данный момент нет четких формальных положений в законе связанные с наличием спорных территорий для сотрудничества на международном уровне, как и при каких условиях, использовать пастбища на приграничных территориях. В свою очередь, данная ситуация часто приводит к захвату пастбищных угодий, несанкционированным пересечениям границ, не законным и тайным выпасом иностранного скота, где наблюдается высокий конфликт интересов и этническую борьбу за использование пастбищ на юге Кыргызстана, в Баткенской области в особенности, где пастбищный комитет не обладает полномочиями разрешать конфликты международного уровня.

References:

1. (n.d.). Zemel'nyy kodeks Kyrgyzskoy Respubliki ot 2 iyunya 1999 goda № 46 - Ministerstvo Yustitsii KR, Retrieved 2019, from http://cbd.minjust.gov.kg/(F(tbbbx3IzfV317bmJ FUNfd2qWaYuGTFeowjfasF17_Qn5H7cg7UD DuFyU7t0ICLOYajqemQoFy0LyAofAE2tMZa xn6o31wTSh5GnkS2RRFPuJ4OtOHDnB6AKe 7AGi-
yYIzalBJcdVltuou9KEjxbxk04UZFaN8Y1rNri CiX6w3U5tFooeCuzSwUUOQgu_6q00))/act/vi ew/ru-ru/211/20?cl=ru-ru

2. (n.d.). Zakon Kyrgyzskoy Respubliki ot 26 yanvarya 2009 goda № 30 - Ministerstvo Yustitsii KR, Retrieved 2019, from http://cbd.minjust.gov.kg/act/view/ru-ru/202594 


\begin{tabular}{llllll} 
& ISRA (India) $=\mathbf{3 . 1 1 7}$ & SIS (USA) $=\mathbf{0 . 9 1 2}$ & ICV (Poland) & $\mathbf{= 6 . 6 3 0}$ \\
Impact Factor: & ISI (Dubai, UAE) $=\mathbf{0 . 8 2 9}$ & PUHL (Russia) $=\mathbf{0 . 1 5 6}$ & PIF (India) & $=\mathbf{1 . 9 4 0}$ \\
& GIF (Australia) $=\mathbf{0 . 5 6 4}$ & ESJI (KZ) $=\mathbf{8 . 7 1 6}$ & IBI (India) & $\mathbf{4 . 2 6 0}$ \\
& JIF & $\mathbf{1 . 5 0 0}$ & SJIF (Morocco) $=\mathbf{5 . 6 6 7}$ & OAJI (USA) & $\mathbf{0 . 3 5 0}$ \\
\hline
\end{tabular}

3. (2018). Undeland, Asyl, Obzor: Zhivotnovodstvo v Kyrgyzstane 2005: 54 str, poluchena dostup, 2018, Retrieved 2019, from https://landportal.org/sites/default/files/kyrgyz livestock_pasture management_and_use.pdf

4. Lim, M. (2012). "Laws, Institutions and Transboundary Pasture Management in the High Pamir and Pamir-Alai Mountain Ecosystem of Central Asia", 8/1 Law, Environment and Development Journal (2012), pp. 43-58. http://www.lead-journal.org/content/12043.pdf

5. Dörre, A. (2012). Legal Arrangements and Pasture-Related Socio-ecological Challenges in Kyrgyzstan. In: Kreutzmann H. (Eds.). Pastoral practices in High Asia. Advances in Asian Human-Environmental Research. Springer, Dordrecht DOI: https://doi.org/10.1007/978-94$\underline{\text { 007-3846-17 }}$

6. Isaeva, A., \& Shigaeva, J. (2017). "Soviet Legacy in the Operation of Pasture Governance Institutions in Present-Day Kyrgyzstan",
Journal of Alpine Research (Revue de géographie alpine) 1 (2017): 4, https://journals.openedition.org/rga/3631

7. (2002). International Crisis Group (ICG), "Central Asia: Border Disputes and Conflict Potential”, ICG Asia Report 33 (2002): 7, Retrieved 2019, from https://www.crisisgroup.org/europe-centralasia/central-asia/tajikistan/central-asia-borderdisputes-and-conflict-potential

8. Toktomushev, K. (2017). "Promoting Social Cohesion and Conflict Mitigation: Understanding Conflict in Cross - Border Areas of Kyrgyzstan and Tajikistan," University of Central Asia, Graduate School of Development, Institute of Public Policy and Administration, Working Paper no. 40 (2017), https://www.ucentralasia.org/Content/Downloa ds/UCA-IPPA-WP-

40_PromotionCrossBorderSocialCohesion_Eng .pdf 